\title{
BMJ open Interrogating a clinical database to study treatment of hypotension in the critically ill
}

\author{
Joon Lee, ${ }^{1}$ Rishi Kothari, ${ }^{2}$ Joseph A Ladapo, ${ }^{3}$ Daniel J Scott, ${ }^{1}$ Leo A Celi ${ }^{1,4}$
}

To cite: Lee J, Kothari R, Ladapo JA, et al. Interrogating a clinical database to study treatment of hypotension in the critically ill. BMJ Open 2012;2:e000916.

doi:10.1136/

bmjopen-2012-000916

- Prepublication history for this paper is available online. To view this file please visit the journal online (http://dx. doi.org/10.1136/ bmjopen-2012-000916).

Received 20 January 2012 Accepted 1 May 2012

This final article is available for use under the terms of the Creative Commons Attribution Non-Commercial 2.0 Licence; see http://bmjopen.bmj.com

${ }^{1}$ Harvard-MIT Division of Health Sciences and Technology, Massachusetts Institute of Technology, Cambridge, Massachusetts, USA

${ }^{2}$ Mount Sinai School of Medicine, New York City, New York, USA

${ }^{3}$ New York University School of Medicine, New York City, New York, USA

${ }^{4}$ Beth Israel Deaconess Medical Center, Boston, Massachusetts, USA

Correspondence to

Dr Joon Lee;

joonlee@mit.edu

\begin{abstract}
Objective: In intensive care, it is imperative to resolve hypotensive episodes (HEs) in a timely manner to minimise end-organ damage. Clinical practice guidelines generally recommend initial treatment with fluid resuscitation followed by vasoactive agent administration if patients remain hypotensive. However, the impact of such interventions on patient outcomes has not been clearly established. Hence, the objective of this study was to investigate the relationship between fluid and vasoactive agent interventions and patient outcomes, while highlighting the utility of electronic medical records in clinical research.
\end{abstract}

Design: Retrospective cohort study.

Setting: Intensive care units (ICUs) at a large, academic, tertiary medical center.

Participants: Patients in Multi-parameter Intelligent Monitoring in Intensive Care II (a large electronic ICU database) who experienced a single HE during their ICU stay. 2332 patients had complete data.

Primary and secondary outcome measures: The primary outcome of interest was inhospital mortality. Secondary outcomes were ICU length of stay (LOS), HE duration, Hypotension Severity Index (defined as the mean arterial pressure curve area below $60 \mathrm{~mm} \mathrm{Hg}$ during the $\mathrm{HE}$ ) and rise in serum creatinine.

Results: Fluid resuscitation was associated with significantly shorter ICU LOS among ICU survivors $(p=0.007)$. Vasoactive agent administration significantly decreased HE duration $(p<0.001)$ and Hypotension Severity Index $(p=0.002)$ but was associated with increased inhospital mortality risk $(p<0.001)$, prolonged ICU LOS among ICU survivors $(p=0.04)$ and rise in serum creatinine $(p=0.002)$ after adjustment for confounders. Propensity score analyses as well as sensitivity analyses in treatment-, diagnosis- and ICU service-specific subpopulations corroborated the relationship between vasoactive agents and increased inhospital mortality.

Conclusions: An adverse relationship between vasoactive agents and inhospital mortality was found in patients with hypotension. This study has implications for the care of critically ill patients with hypotension and illustrates the utility of electronic medical records in research when randomised controlled trials are difficult to conduct.

\section{ARTICLE SUMMARY}

\section{Article focus}

- To investigate the impact of fluid resuscitation and vasoactive therapy on patient outcomes in critically ill patients who experienced a $\mathrm{HE}$, using an electronic database.

- To emphasise the utility of electronic medical records in clinical research when prospective randomised clinical trial results are absent.

\section{Key messages}

- Vasoactive agents were found to be correlated with increased inhospital mortality risk, even after propensity adjustment.

- Electronic medical records can help answer clinical questions for which clinical trials are challenging to conduct.

Strengths and limitations of this study

- The adverse relationship between vasoactive agents and inhospital mortality was carefully established using propensity score and sensitivity analyses.

- The results of this paper are thought provoking but inconclusive. It is possible that vasoactive agents harm only a specific subset of the critically ill.

\section{INTRODUCTION}

Electronic medical records (EMRs) that include detailed information on clinical care afford researchers a unique opportunity to evaluate both practice variation and the impact of diagnostic and therapeutic decisions on patient outcomes. When compiled into clinical databases and used for research purposes, they have potential advantages compared with randomised controlled trials (RCT). For example, clinical databases built using EMRs require fewer resources to mobilise for analysis, are capable of including readily accessible information on large and diverse patient populations and allow research questions to be answered within a shorter period of time. Their versatility also 
makes them a potential resource for policymakers, as public and private healthcare payers increasingly rely on clinical evidence to support practice guidelines and coverage decisions. Another advantage associated with EMRs is that they can be used to assess interventions in real-life practice, whereas RCTs tend to focus on arguably artificial clinical scenarios stemming from their strict inclusion and exclusion criteria.

The Multi-parameter Intelligent Monitoring in Intensive Care II (MIMIC-II) Database ${ }^{1}$ is a clinical database that provides detailed information about the care of patients treated in intensive care units (ICUs). Critically ill patients are an ideal population for clinical database investigations because the clinical value of many treatments and interventions they receive is unproven, and high-quality data supporting or discouraging specific practices is relatively sparse. ${ }^{2}{ }^{3}$ We used MIMIC-II to explore practice variation and health outcomes in critically ill patients admitted for or later developing hypotension in an ICU. Hypotension is an important condition to study in this setting because it is a risk factor for hospital mortality and approaches to its treatment vary widely (eg, colloids vs crystalloids for fluid resuscitation $^{45}$ ). Moreover, many of the interventions used to treat hypotension are associated with adverse events including pulmonary oedema, heart failure and tissue ischaemia. $^{6-9}$

\section{METHODS}

Study population

This study utilised the MIMIC-II Database (version 2.6), a publicly available clinical database developed through a collaboration among Massachusetts Institute of Technology, Philips Healthcare and Beth Israel Deaconess Medical Center. ${ }^{1}$ MIMIC-II is a repository of de-identified physiologic, laboratory, and survival outcome data from approximately 25000 critically ill adult patients cared for in the ICUs at Beth Israel Deaconess Medical Center between 2001 and 2008. These data include clinical variables such as patient age, gender and chronic disease diagnoses as represented by International Classification of Diseases (ICD) codes; laboratory data such as haematocrit, creatinine and electrolytes; physiologic data such as blood pressure and heart rate; markers of treatment intensity such as the utilisation of invasive and non-invasive mechanical ventilation, renal replacement therapy, central venous lines, vasoactive agents and blood transfusion and survival during and after the hospitalisation.

Patients in MIMIC-II who were cared for in medical ICUs (MICU), surgical ICUs (SICU), coronary care units (CCU) and cardiac surgery recovery units (CSRU) were included in the study. In addition, patients were eligible for inclusion in this study if they experienced a single hypotensive episode (HE), and their code status was not comfort measures only within $24 \mathrm{~h}$ before and after the HE. Hypotension was defined based on mean arterial pressure (MAP) measurements obtained either by inva- sive arterial catheters or non-invasive sphygmomanometers. Both types of measurement were usually recorded every 10-15 min in our cohort; although invasive arterial catheters yield beat-by-beat blood pressure, we utilised nurse-verified measurements that are still recorded every 10-15 min. The beginning of an HE was defined as the time of the first of two consecutive MAP measurements $\leq 60 \mathrm{~mm} \mathrm{Hg}$, preceded by two consecutive MAP values above $60 \mathrm{~mm} \mathrm{Hg}$. The end of an $\mathrm{HE}$ was defined as the time of the first of two consecutive MAP measurements $>60 \mathrm{~mm} \mathrm{Hg}$, preceded by two consecutive MAP values $\leq 60 \mathrm{~mm} \mathrm{Hg}$. A MAP threshold of $60 \mathrm{~mm} \mathrm{Hg}$ was used in the study based on the finding that autoregulation ceases and blood flow becomes pressure dependent below this level in various organs. ${ }^{10}$

\section{Study variables and outcomes}

The two primary independent variables of interest were administration of intravenous fluid and initiation or increase in dosage of vasoactive agents during the HE. Fluid resuscitation was defined as at least one infusion of either a bolus of isotonic crystalloid of at least $250 \mathrm{ml}$ or any volume of colloids. Vasoactive therapy was defined as an initiation or a dosage increase of dobutamine, dopamine, epinephrine, norepinephrine, phenylephrine or vasopressin during the HE. Not all patients received fluids or vasoactive agents during their HE.

The primary patient outcome was inhospital mortality, while the secondary outcomes were ICU length of stay (LOS) longer than 3 days, HE duration longer than $1 \mathrm{~h}$, Hypotension Severity Index (HSI), defined as the MAP curve area below $60 \mathrm{~mm} \mathrm{Hg}$ during the $\mathrm{HE}$ and any increase in serum creatinine level within 3 days following the HE. Figure 1 illustrates how we calculated HSI for each HE. HSI approximates the area between linearly interpolated mean blood pressure measurements and the $60 \mathrm{~mm} \mathrm{Hg}$ and captures both $\mathrm{HE}$ duration and magnitude of blood pressure in one metric. The unit of HSI is $\mathrm{mm} \mathrm{Hg} \cdot \mathrm{min}$. As an outcome variable, HSI was first calculated as a continuous value and subsequently dichotomised with a threshold of $150 \mathrm{~mm} \mathrm{Hg} \cdot \mathrm{min}$ (roughly the median HSI in the cohort). ICU LOS was investigated in all patients, as well as only among the patients who survived their ICU stay.

Control variables in this study included age, gender, Simplified Acute Physiologic Score (SAPS) (a predictor of mortality for critically ill patients), an Elixhauser comorbidity score $^{11}$ calculated using the method described by Van Walraven et $a l^{12}$ (indicator of chronic illness and secondary diagnoses), mean MAP in the $3 \mathrm{~h}$ period immediately prior to the $\mathrm{HE}$ onset (measure of haemodynamic status before the HE), total volume of urine output in the 3-h period immediately prior to the $\mathrm{HE}$ onset $>200 \mathrm{ml}$ (surrogate measure of organ perfusion), last serum creatinine level prior to and within $24 \mathrm{~h}$ of the HE onset (another surrogate measure of organ perfusion) and service type (MICU, SICU, CCU or CSRU). In addition, all propensity score models in this study (to be discussed in the Statistical analysis section) 
Figure 1 A pictorial illustration of Hypotension Severity Index (HSI) calculation. The greyed area in $\mathrm{mm} \mathrm{Hg} \cdot \min$ represents the $\mathrm{HSI}$ in this particular case. Consecutive mean blood pressure measurements are linearly interpolated, and the area below $60 \mathrm{~mm} \mathrm{Hg}$ from the first to last measurement of the hypotensive episodes (HE) is computed. HSI has the advantage of harnessing both magnitude of mean blood pressure and HE duration.

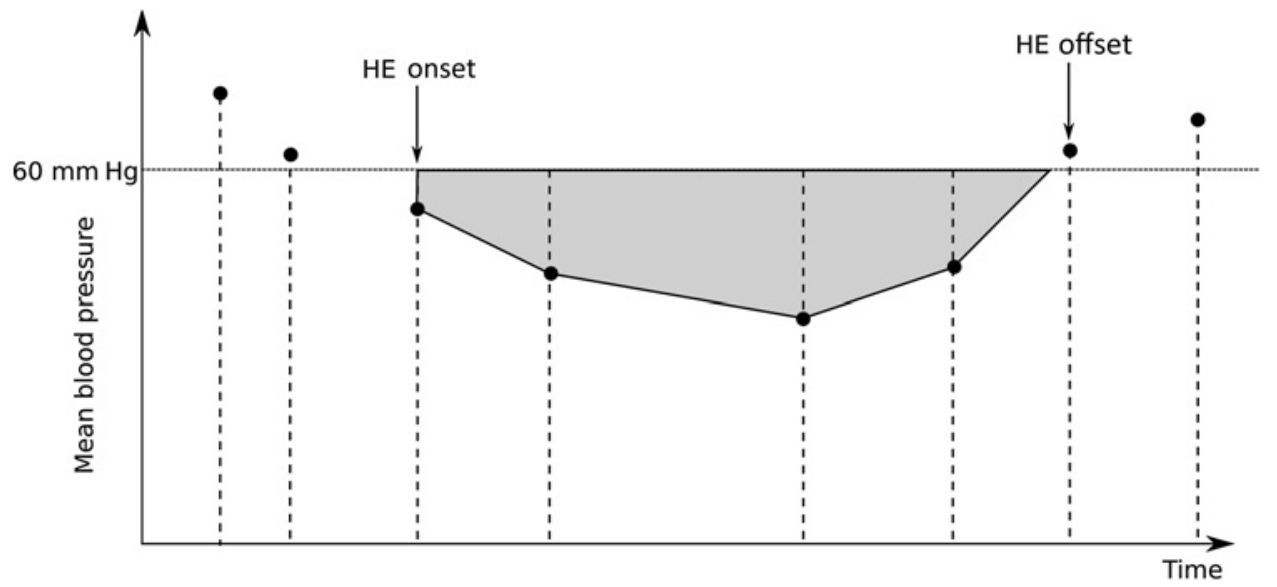

included the total volume of fluids (normal saline and lactated ringer) given to the patient between ICU admission and the beginning of the HE.

\section{Statistical analysis}

The effects of hypotension treatment approaches on patient outcomes were investigated after adjusting for confounding variables using multivariate logistic regression. For each logistic regression model, the Hosmer-Lemeshow (H-L) goodness-of-fit test $^{13}$ and receiver operating characteristic curve analysis were performed to evaluate the calibration and discrimination of the model, respectively. For all outcomes, $\mathrm{p}$ values $<0.05$ were considered significant.

In order to further address omitted variable bias in the inhospital mortality analysis, a propensity score analysis ${ }^{14}$ was employed to adjust for the likelihood of receiving vasoactive therapy. A logistic regression model with all control variables was built to estimate propensity scores for receipt of vasoactive therapy, while remaining blind to inhospital mortality. Propensity scores were then used in a subsequent regression model as a regressor along with the primary predictors (fluids and vasoactive agents), while the outcome variable was inhospital mortality.

As a sensitivity analysis, inhospital mortality with and without adjustment using propensity scores was analysed after excluding patients who received neither fluids nor vasoactive agents during their $\mathrm{HE}$. By focusing only on treated patients, patients with a potentially clinically unimportant HE were excluded. Similarly, inhospital mortality with and without propensity score adjustment was also investigated within patients who received either only fluids or both fluids and vasoactive agents (in other words, fluid-resuscitated patients, who comprise a subset of the treated patients). By excluding patients who received only vasoactive agents and no fluids during their HE, this sensitivity analysis reduced the number of patients whose clinical presentations were more severe.

In addition, differences across the four service types in the underlying cause of hypotension, and hence in hypotension treatment methods, were addressed by conducting an ICU service-specific sensitivity analysis. Specifically, a separate propensity score model was built in each service type to investigate inhospital mortality. We also performed subgroup analyses among patients with sepsis and among patients with congestive heart failure (CHF) based on ICD-9 codes. The rationale was to address potential bias by indication. Separate logistic regression models with propensity score adjustment were constructed for these analyses.

All statistical analyses were performed using MATLAB version R2010b (MathWorks, Natick, Massachusetts, USA).

\section{RESULTS}

A total of 3163 patients in MIMIC-II met the inclusion criteria. Of these patients, $63.3 \%$ and $81.6 \%$ developed an HE within 24 and 48 h of ICU admission, respectively. Table 1 summarises the demographic and clinical characteristics of the patients in our cohort. The median HE duration was $2 \mathrm{~h}$. Most HEs $(62.9 \%)$ were treated with neither fluids nor vasoactive agents, whereas $19.8 \%$ of the patients were fluid resuscitated. The incidence of vasoactive agent use was $17.3 \%$ as monotherapy and $6.3 \%$ in combination with fluids. The inhospital mortality of the patient cohort was $12.9 \%$, while the median ICU LOS was 2.7 days. Of the 3163 patients, 732 and 354 were $\mathrm{CHF}$ and sepsis patients, respectively. Also, 1486 and 1677 patients were monitored using invasive and non-invasive blood pressure measurement techniques, respectively.

Table 2 summarises results for inhospital mortality stratified by treatment. Of the 3163 patients, 2332 had complete data and were included in multivariate analyses. The largest contributor to missing data was serum creatinine. While no significant relationship was found between fluid resuscitation and inhospital mortality, vasoactive therapy was associated with an increased inhospital mortality risk in all $(\mathrm{OR}=2.86, \mathrm{p}<0.001)$, treated (received either fluids or vasoactive agents, or both $) \quad(\mathrm{OR}=2.41, \mathrm{p}=0.02)$, and fluid resuscitated patients (received either only fluids or both fluids and vasoactive agents $)(\mathrm{OR}=2.30, \mathrm{p}=0.04)$. Among the 
Table 1 Demographic and clinical characteristics of the study population $(\mathrm{N}=3163)$

\begin{tabular}{|c|c|}
\hline Age $^{*}$ (years) & $69.3(56.9,79.3)$ \\
\hline Gender (male) & $54.3 \%$ \\
\hline \multicolumn{2}{|l|}{ Service type } \\
\hline MICU & $33.2 \%$ \\
\hline SICU & $22.0 \%$ \\
\hline $\mathrm{CCU}$ & $15.8 \%$ \\
\hline CSRU & $29.0 \%$ \\
\hline SAPS I* & $15(11,19)$ \\
\hline HE duration* (min) & $120(45,120)$ \\
\hline \multicolumn{2}{|l|}{ Hypotension treatment } \\
\hline No intervention & $62.9 \%$ \\
\hline Fluids only & $13.5 \%$ \\
\hline Vasoactive agents only & $17.3 \%$ \\
\hline Both fluids and vasoactive agents & $6.3 \%$ \\
\hline Inhospital mortality & $12.9 \%$ \\
\hline ICU LOS* (days) & $2.7(1.6,4.9)$ \\
\hline \multicolumn{2}{|l|}{ Elixhauser comorbidities } \\
\hline Congestive heart failure & $20.9 \%$ \\
\hline Cardiac arrhythmias & $21.0 \%$ \\
\hline Valvular disease & $8.6 \%$ \\
\hline Pulmonary circulation disorders & $2.4 \%$ \\
\hline Peripheral vascular disorders & $9.5 \%$ \\
\hline Hypertension & $30.9 \%$ \\
\hline Paralysis & $1.1 \%$ \\
\hline Other neurological disorders & $3.3 \%$ \\
\hline Chronic pulmonary disease & $16.4 \%$ \\
\hline Diabetes, uncomplicated & $21.2 \%$ \\
\hline Diabetes, complicated & $4.8 \%$ \\
\hline Hypothyroidism & $8.7 \%$ \\
\hline Renal failure & $5.1 \%$ \\
\hline Liver disease & $4.6 \%$ \\
\hline $\begin{array}{l}\text { Peptic ulcer disease excluding } \\
\text { bleeding }\end{array}$ & $0.5 \%$ \\
\hline AIDS & $0.6 \%$ \\
\hline Lymphoma & $1.5 \%$ \\
\hline Metastatic cancer & $4.4 \%$ \\
\hline Solid tumour without metastasis & $10.8 \%$ \\
\hline $\begin{array}{l}\text { Rheumatoid arthritis/collagen } \\
\text { vascular disease }\end{array}$ & $2.2 \%$ \\
\hline Coagulopathy & $6.1 \%$ \\
\hline Obesity & $1.6 \%$ \\
\hline Weight loss & $2.7 \%$ \\
\hline Fluid and electrolyte disorders & $24.3 \%$ \\
\hline Blood loss anaemia & $0 \%$ \\
\hline Deficiency anaemias & $11.9 \%$ \\
\hline Alcohol abuse & $3.7 \%$ \\
\hline Drug abuse & $1.8 \%$ \\
\hline Psychoses & $2.3 \%$ \\
\hline Depression & $4.1 \%$ \\
\hline $\begin{array}{l}\text { *Median }\left(\mathrm{Q}_{1}, \mathrm{Q}_{3}\right) \text {. } \\
\mathrm{CCU} \text {, coronary care unit; CSRU, cardiac } \\
\text { hypotensive episode; LOS, length of stay } \\
\text { care unit; SAPS, Simplified Acute Physiol } \\
\text { intensive care unit. }\end{array}$ & $\begin{array}{l}\text { recovery unit; HE, } \\
\text { medical intensive } \\
\text { re; SICU, surgical }\end{array}$ \\
\hline
\end{tabular}

control variables, older age, higher SAPS, higher Elixhauser, higher mean MAP prior to the HE, lower urine output prior to the HE and MICU (in comparison to SICU, CCU and CSRU) were significantly associated with higher inhospital mortality in the overall cohort. Among the treated patients only, higher SAPS, higher Elixhauser, lower urine output prior to the HE and MICU (in comparison to CSRU) were associated with higher inhospital mortality. The multivariate analysis of fluidresuscitated patients showed that higher SAPS, higher Elixhauser, lower urine output prior to the $\mathrm{HE}$ and MICU (in comparison to CCU and CSRU) were all associated with an increased risk of death.

In estimating the propensity for vasoactive therapy in the entire patient cohort, younger age, male gender, higher SAPS, higher Elixhauser, lower urine output prior to the HE and CSRU (in comparison to MICU) were significantly correlated with higher likelihood of receiving vasoactive agents. In the treated patients, higher SAPS, higher Elixhauser, higher serum creatinine prior to the HE and CSRU (in comparison with MICU) were significant predictors of vasoactive therapy. Among the patients who received fluid resuscitation, higher SAPS, higher serum creatinine prior to the $\mathrm{HE}$ and CSRU (in comparison with MICU) were associated with increased propensity. See table AI for detailed results of the propensity score calculation models.

Table 3 summarises the relationship between vasoactive therapy and inhospital mortality after propensity score adjustment. Vasoactive therapy remained significantly associated with increased mortality, in all $(\mathrm{OR}=2.44, \mathrm{p}<0.001)$, treated $(\mathrm{OR}=2.21, \mathrm{p}=0.009)$ and fluid-resuscitated patients $(\mathrm{OR}=1.03, \mathrm{p}=0.02)$. However, in comparison with our results in table 2, the corresponding vasoactive agent ORs for inhospital mortality decreased, most substantially in patients who received fluid resuscitation (from 2.30 to 1.03 ).

The results from the ICU service-specific analysis are tabulated in tables AII and AIII. After propensity adjustment, the relationship between vasoactive agents and higher inhospital mortality remained significant in all service types except CSRU. Fluid resuscitation was not significantly correlated with inhospital mortality in any service type.

Our subgroup analyses yielded similar findings as the main analyses. In the 732 patients with $\mathrm{CHF}$, vasoactive therapy remained significantly correlated with inhospital mortality after propensity score adjustment $(\mathrm{OR}=2.00$, $\mathrm{p}=0.004$ ). Likewise, in the 354 sepsis patients, vasoactive therapy was a significant predictor of in-hospital mortality with propensity score adjustment $(\mathrm{OR}=2.84, \mathrm{p}<0.001)$.

Table 4 provides the multivariate logistic regression results for the secondary outcomes in all patients. We found that fluid resuscitation was significantly associated with shorter ICU LOS (all patients: $O R=0.71, p=0.004$; ICU survivors: $O R=0.71, p=0.007$ ) and greater HSI $(\mathrm{OR}=1.26, \mathrm{p}=0.04)$. Vasoactive agent administration was significantly associated with longer ICU LOS among ICU survivors $(\mathrm{OR}=1.29, \mathrm{p}=0.04)$, shorter $\mathrm{HE}$ duration $(\mathrm{OR}=0.29, \quad \mathrm{p}<0.001), \quad$ decreased HSI $\quad(\mathrm{OR}=0.72$, $\mathrm{p}=0.002)$, and rise in serum creatinine $(\mathrm{OR}=1.44$, $\mathrm{p}=0.002)$. 
Table 2 Multivariate logistic regression results for inhospital mortality

\begin{tabular}{|c|c|c|c|}
\hline & $\begin{array}{l}\text { All patients, } \\
\text { OR }(95 \% \mathrm{Cl})\end{array}$ & $\begin{array}{l}\text { Treated patients, } \\
\text { OR }(95 \% \mathrm{Cl})\end{array}$ & $\begin{array}{l}\text { Fluid-resuscitated patients, } \\
\text { OR }(95 \% \mathrm{Cl})\end{array}$ \\
\hline Fluid resuscitation & $0.87(0.61$ to 1.26$)$ & $0.75(0.40$ to 1.40$)$ & NA \\
\hline Use of vasoactive agents & $2.86^{*}(2.09$ to 3.92$)$ & $2.41^{*}(1.19$ to 4.88$)$ & $2.30^{*}(1.05$ to 5.03$)$ \\
\hline Age (year) & $1.01^{*}(1.00$ to 1.02$)$ & 1.01 (0.99 to 1.02$)$ & $1.02(1.00$ to 1.05$)$ \\
\hline Gender (male) & $0.96(0.72$ to 1.27$)$ & $0.93(0.59$ to 1.47$)$ & $0.82(0.40$ to 1.67$)$ \\
\hline SAPS & $1.14^{*}(1.11$ to 1.18$)$ & $1.17^{*}(1.12$ to 1.22$)$ & $1.18^{*}(1.10$ to 1.27$)$ \\
\hline Elixhauser & $1.24^{*}(1.14$ to 1.36$)$ & $1.15^{\star}(1.01$ to 1.32$)$ & $2.00^{\star}(1.26$ to 3.17$)$ \\
\hline Mean MAP prior to $\mathrm{HE}(\mathrm{mm} \mathrm{Hg})$ & $1.02^{*}(1.00$ to 1.03$)$ & $1.02(1.00$ to 1.04$)$ & $1.02(0.99$ to 1.06$)$ \\
\hline Urine output prior to $\mathrm{HE}>200 \mathrm{ml}$ & $0.65^{\star}(0.49$ to 0.87$)$ & $0.57^{*}(0.35$ to 0.91$)$ & $0.30^{*}(0.13$ to 0.68$)$ \\
\hline Creatinine prior to HE (mg/dl) & 1.07 (0.96 to 1.19$)$ & $1.07(0.90$ to 1.28$)$ & $1.05(0.75$ to 1.49$)$ \\
\hline \multicolumn{4}{|l|}{ Service type } \\
\hline MICU† & 1 & 1 & 1 \\
\hline SICU & $0.62^{*}(0.43$ to 0.88$)$ & $0.62(0.35$ to 1.08$)$ & $0.37^{*}(0.15$ to 0.91$)$ \\
\hline $\mathrm{CCU}$ & $0.63^{*}(0.42$ to 0.94$)$ & $0.61(0.32$ to 1.14$)$ & $0.25^{\star}(0.07$ to 0.86$)$ \\
\hline CSRU & $0.08^{*}(0.05$ to 0.14$)$ & $0.05^{\star}(0.02$ to 0.11$)$ & $0.14^{*}(0.05$ to 0.41$)$ \\
\hline Number of subjects & 2332 & 812 & 409 \\
\hline AUC & 0.831 & 0.868 & 0.877 \\
\hline Hosmer-Lemeshow $p$ value & 0.37 & 0.40 & 0.86 \\
\hline
\end{tabular}

\section{DISCUSSION}

Clinical databases built using EMRs such as MIMIC-II represent an opportunity to study clinical areas where practice variation exists or care standards have not been established. In this study, we examined treatment of hypotension in the ICU. The decision to administer intravenous fluids or vasoactive agents, and the volume or dose chosen, largely depend on the clinician's preferences and practice patterns within an ICU, along with process-related factors at the time of the hypotensive event (eg, physician presence at the bedside, nurse-topatient ratio, etc). ${ }^{15}$ Clinician decision-making, in the absence of strong guidelines, is frequently driven by prior experience, which is particularly prevalent in intensive care where RCT evidence is relatively sparse. $^{16}{ }^{17}$ This results in significant care variability not explained by patient or contextual factors but instead driven by individual provider practice. Use of inotropes, for example, has been described as both hospital and physician dependent, being administered to as few as $5 \%$ or to as many as $100 \%$ of patients undergoing elective cardiac surgery. $^{18} 19$

In our retrospective analysis, we did not find significant variation in the rate of fluid administration, with majority of the patients receiving between 250 and $500 \mathrm{ml} / \mathrm{h}$. The limited variability in fluid administration volume may explain why we did not find a relationship between fluid administration and inhospital mortality or

Table 3 Vasoactive therapy propensity score analysis results for inhospital mortality

\begin{tabular}{|c|c|c|c|}
\hline & $\begin{array}{l}\text { All patients, } \\
\text { OR }(95 \% \mathrm{Cl})\end{array}$ & $\begin{array}{l}\text { Treated patients, } \\
\text { OR }(95 \% \mathrm{Cl})\end{array}$ & $\begin{array}{l}\text { Fluid-resuscitated } \\
\text { patients, OR }(95 \% \mathrm{Cl})\end{array}$ \\
\hline Fluid resuscitation & $0.97(0.70$ to 1.33$)$ & $0.87(0.54$ to 1.41$)$ & NA \\
\hline Use of vasoactive agents & $2.44^{*}(1.85$ to 3.20$)$ & $2.21^{*}(1.22$ to 4.01$)$ & $1.03^{*}(1.00$ to 1.05$)$ \\
\hline Propensity for vasoactive therapy & $2.03(0.83$ to 5.00$)$ & $0.96(0.28$ to 3.24$)$ & $5.41^{*}$ (1.12 to 26.26$)$ \\
\hline Number of subjects & 2332 & 812 & 409 \\
\hline AUC & 0.621 & 0.602 & 0.629 \\
\hline Hosmer-Lemeshow p value & 0.01 & 0.02 & 0.03 \\
\hline
\end{tabular}




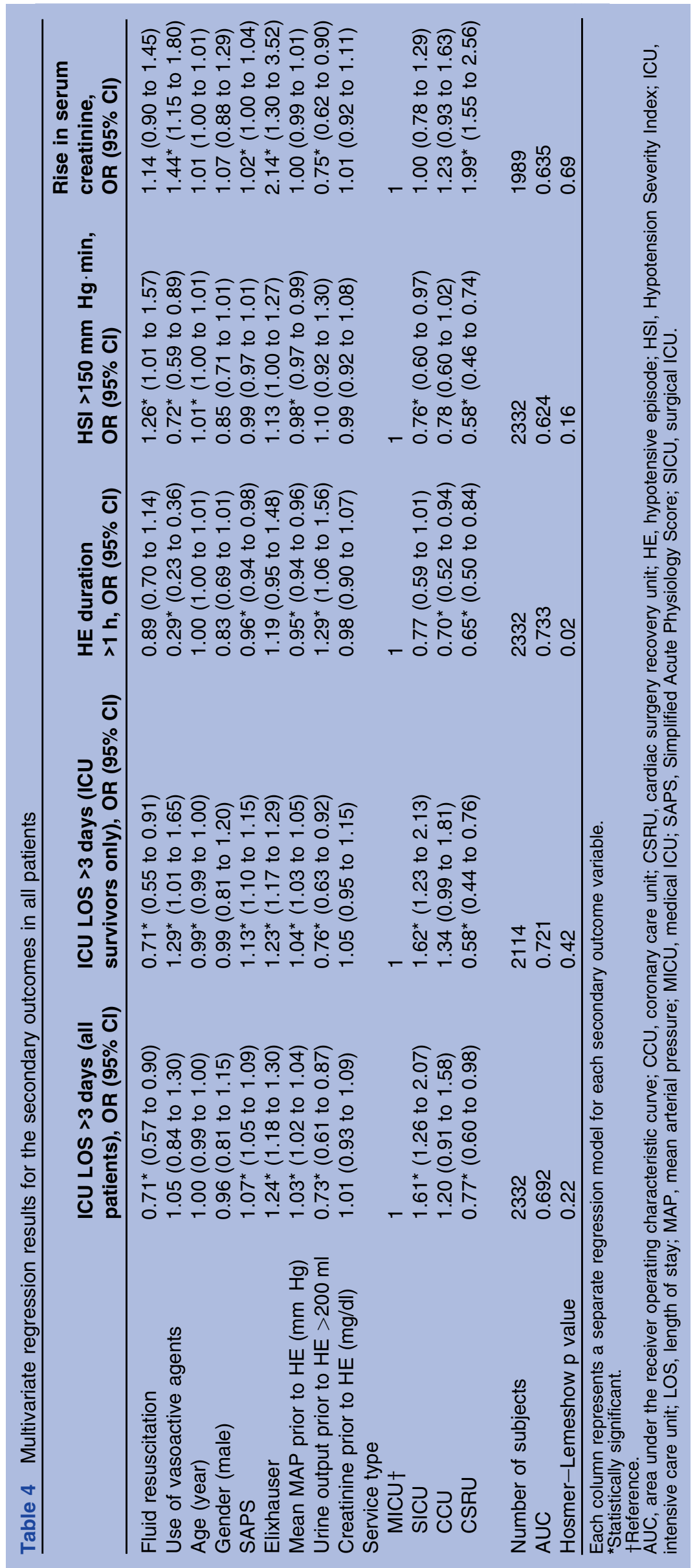


some of our secondary outcomes. The administration of vasoactive agents, however, was an independent predictor of inhospital mortality, and this relationship persisted in the propensity score analysis. To address the issue of confounding by indication, multivariate logistic regression and propensity score analyses were performed in each service type as well as in subsets of patients with CHF or sepsis. In all of these analyses except in CSRU patients, vasoactive agent use remained independently associated with inhospital mortality.

Other studies have also reported that vasoactive therapy may be associated with higher mortality. Shahin and colleagues ${ }^{20}$ found that hospital mortality and renal dysfunction were consistently lower in patients unexposed to inotropes, even when their 6-h physiologic variables were lower than literature-recommended targets. In patients with heart failure, a systematic review of controlled trials of catecholaminergic agents compared with placebo found no improvement in patient outcomes-indeed, there was evidence of harm. ${ }^{21}$ Using data from the multi-centre trial of N-omega-monomethylL-arginine (L-NMMA) in septic shock, Dunser et $a t^{22}$ found that mean vasoactive agent load was associated with higher 28-day mortality.

Catecholamines have a wide range of potential adverse effects, ${ }^{6}$ including excess vasoconstriction and impaired microcirculation leading to impaired organ perfusion and increased metabolic demands, including myocardial oxygen requirement. Furthermore, catecholamine use has been associated with reduced metabolic efficiency by promoting fatty acid oxidation. Catecholamines have also been associated with increased bacterial virulence and biofilm formation and altered immune response. $^{6} 2324$

Clinical guidelines for the management of sepsis ${ }^{25}$ and cardiogenic shock ${ }^{26}$ recommend fluid resuscitation and vasopressor/inotropic support. However, they also state that the recommendations are based on a low level of evidence. Furthermore, in a review article regarding cardiogenic shock, Reynolds and Hochman ${ }^{27}$ have suggested that the lowest possible doses should be administered when vasopressor and inotropic agents are used, due to a possible relationship between high doses of vasoactive agents and worse survival outcomes. ${ }^{28}$

Clinical databases built using EMRs may be ideal resources for evaluating the impact of vasoactive agents on outcomes. Randomised placebo-controlled clinical trials for commonly used vasoactive agents are either unavailable or lack sufficient statistical power to evaluate differences in important clinical outcomes. ${ }^{25}$ Our study was not able to address whether the observed increase in hospital mortality was more likely to occur with some vasoactive agents than others due to inadequate power. De Backer $e t a l^{29}$ found no significant difference in 28day mortality between patients who received dopamine as first-line vasopressor therapy and those who received norepinephrine, although dopamine use was associated with significantly more arrhythmias. In our cohort, there were 76 and 171 patients who received only dopamine and norepinephrine, respectively. The unadjusted inhospital mortality rates in the dopamine and norepinephrine groups were $39.5 \%$ and $32.8 \%$, respectively.

It is important to note that, despite our use of propensity scores, residual confounding remains a concern. We attempted to address this by repeating our analyses in patient subsets, but we may not have fully adjusted for severity of illness. Little data elsewhere exist that examine the impact of vasoactive agents on endorgan preservation. This area may be a promising one for clinical trials.

There are a few limitations associated with the present study. First, potential bias stemming from missing data abounds. Of the 3163 patients who met the inclusion criteria, 2332 had complete data and were analysed. Second, the duration and dosage of vasoactive therapy during the HE were not investigated. The analysis was restricted to the identified HEs; the use of vasoactive agents throughout the ICU stay outside the HE was not evaluated. Third, although we included the total amount of fluids given to the patient prior to the HE in the propensity score models, an assessment of fluid responsiveness was not included in the models. Traditional static measures such as central venous pressure were not consistently obtained among the patients and have been shown to be poorly predictive of fluid responsiveness. ${ }^{30}$ Dynamic measures have not been sufficiently standardised and validated across critically ill patients, especially those who are spontaneously breathing, those who are mechanically ventilated but not deeply sedated or those who have cardiac arrhythmias. We made the assumption that vasoactive agents were initiated or their dose increased after clinician assessment that the patient will not benefit from additional fluid administration.

Alternative interpretations of our findings are possible. It may be that the adverse relationship between vasoactive agents and survival actually comprises a combination of incremental benefits in a subset of patients that are outweighed by incremental harms in another subset. The threshold blood pressure below which end-organ damage ensues likely differs among patients and perhaps even within the same patient in different clinical contexts. The clinical challenge is to predict the lowest blood pressure threshold for which no treatment is required. The concept of permissive hypotension has been introduced in the neonatal intensive care literature based on findings of similar outcomes between normotensive and hypotensive low birth weight infants with signs of good perfusion. ${ }^{31}$ Permissive hypotension would be challenging to investigate prospectively; however, analyses with robust electronic medical records may hold the key to unravelling this conundrum.

Our study is a first step in examining management of hypotension in the ICU, and it suggests potential areas of investigation and standardisation of processes of care. The frequency of vasoactive agent use in the ICU may have engendered a perception of safety. Titration of 
haemodynamic interventions such as vasoactive therapy using a fixed blood pressure target is straightforward to apply at the bedside and likely perceived as rewarding to the staff. Personalised guidelines that are patient and context specific may be more beneficial, particularly when treatment is associated with significant harm. Robust customisation of hypotensive thresholds may be best achieved by utilising extensive real-time modelling of physiologic variables on a patient-by-patient basis. Prospectively, prediction of outcomes with vasoactive therapy may be sought with the help of growing clinical databases to create treatment algorithms.

In a previous study, Celi $e t a \hat{l}^{2}$ introduced a method of designing decision support tools based on a hospital's own clinical database as an alternative to expert systems derived from large, multi-centre, interventional or observational studies. Using the term 'Collective Experience' to refer to the aggregation of patient care data from clinicians working in a single institution, they proposed developing guideline models from a more homogeneous group of patients because of the trade-off between generalisability and accuracy. The utility of a local EMR in clinical decision support when the existing literature lacks relevant evidence was also discussed by Frankovich et al. ${ }^{33}$ Clinical guidelines developed by a single institution may provide diagnostic assistance, treatment guidance and prognostic capabilities that are more personalised and appropriate for an institution's patient population. The vision is a data-fuelled learning system that aggregates and analyzes day-to-day experimentations, where new knowledge is constantly extracted and propagated for quality improvement and where practice is driven by outcomes and less so by individual clinician knowledge base and experience and the local medical culture.

\section{CONCLUSIONS}

Using an EMR, we found that patients who were exposed to vasoactive therapy during HEs were more likely to die, a finding consistent with other studies in sepsis, cardiac surgery and heart failure. Clinical databases such as MIMIC-II can complement knowledge gained from conventional comparative effectiveness research methods and provide important insights about routine patient care.

Contributors $\mathrm{JL}$ designed the study, conducted data extraction and analyses and wrote most parts of the manuscript. RK designed the study, helped with data extraction and critically revised the manuscript. JAL wrote the discussion section and critically revised the manuscript. DJS helped with data extraction and critically revised the manuscript. LAC designed the study, wrote the discussion section and critically revised the manuscript. JL and LAC are the guarantors of the study. All authors had full access to all of the data.

Funding This research was supported by grant R01 EB001659 from the National Institute of Biomedical Imaging and Bioengineering (NIBIB) of the National Institutes of Health (NIH). JL also holds a Postdoctoral Fellowship from the Natural Sciences and Engineering Research Council of Canada.

Competing interests None.

Ethics approval The study used a public de-identified database and the IRB approval was waived.

Provenance and peer review Not commissioned; externally peer reviewed.
Data sharing statement There is no additional data available. This study was conducted based on the public MIMIC-II database. Any interested researcher can gain access to MIMIC-II for details, please see http://physionet. org/mimic2/

\section{REFERENCES}

1. Saeed M, Villarroel M, Reisner AT, et al. Multiparameter Intelligent Monitoring in Intensive Care II (MIMIC-II): a public-access intensive care unit database. Crit Care Med 2011;39:952-60. http://www.ncbi. nlm.nih.gov/pubmed/21283005

2. Vincent JL, Singer M. Critical care: advances and future perspectives Lancet 2010;376:1354-61. http://discovery.ucl.ac.uk/1306941/

3. Vincent JL. Is the current management of severe sepsis and septic shock Really evidence based? PLoS Med 2006;3:e346.

4. Choi PT, Yip G, Quinonez LG, et al. Crystalloids vs. colloids in fluid resuscitation: a systematic review. Crit Care Med 1999;27:200-10. http://www.ncbi.nlm.nih.gov/pubmed/9934917

5. Perel P, Roberts I. Colloids versus crystalloids for fluid resuscitation in critically ill patients. Cochrane Database Syst Rev 2011;(3): CD000567. http://www.ncbi.nlm.nih.gov/pubmed/15495001

6. Singer M. Catecholamine treatment for shock-equally good or bad? Lancet 2007;370:636-7. http://www.ncbi.nlm.nih.gov/pubmed/ 17719998

7. Parissis JT, Rafouli-Stergiou P, Stasinos V, et al. Inotropes in cardiac patients: update 2011. Curr Opin Crit Care 2010;16:432-41. http:// www.ncbi.nlm.nih.gov/pubmed/20711077

8. Brandt $\mathrm{S}$, Regueira $\mathrm{T}$, Bracht $\mathrm{H}$, et al. Effect of fluid resuscitation on mortality and organ function in experimental sepsis models. Crit Care 2009;13:R186. http://ccforum.com/content/13/6/R186

9. Groeneveld AJ. Fluids in septic shock: too much of a good thing? Crit Care 2010;14:101. http://www.ncbi.nlm.nih.gov/pubmed/20092608

10. Wendon J. Critical care "normality": individualized versus protocolized care. Crit Care Med2010;38(10 Suppl):S590-9. http://www.ncbi.nIm. nih.gov/pubmed/21164402

11. Elixhauser A, Steiner C, R Harris D, et al. Comorbidity measures for use with administrative data. Med Care 1998;36:8-27. http://www. mendeley.com/research/comorbidity-measures-administrative-data-1/

12. Van Walraven $C$, Austin PC, Jennings A, et al. A modification of the Elixhauser comorbidity measures into a point system for hospital death using administrative data. Med Care 2009;47:626-33. http:// journals.Iww.com/lww-medicalcare/Abstract/2009/06000/A Modification_of_the_Elixhauser_Comorbidity.4.aspx

13. Hosmer D, Lemeshow S. Applied Logistic Regression. Hoboken, NJ: John Wiley \& Sons, 2000.

14. D'Agostino RB. Propensity score methods for bias reduction in the comparison of a treatment to a non-randomized control group. Stat Med 1998;17:2265-81. http://www.ncbi.nlm.nih.gov/pubmed/9802183

15. Takala J. Should we target blood pressure in sepsis? Crit Care Med 2010;38(10 Suppl):S613-19. http://content.wkhealth.com/linkback/ openurl?sid=WKPTLP:landingpage $\&$ an $=00003246-201010001-00017$

16. Angus DC. Caring for the critically ill patient: challenges and opportunities. J Am Med Assoc 2007;298:456-8. http://jama.amaassn.org/cgi/content/full/298/4/456

17. Angus DC, Linde-Zwirble WT, Sirio CA et al. The effect of Managed care on ICU length of stay. J Am Med Assoc 1996;276:1075-82. http://jama.ama-assn.org/content/276/13/1075.abstract

18. Kastrup M, Markewitz A, Spies C, et al. Current practice of hemodynamic monitoring and vasopressor and inotropic therapy in post-operative cardiac surgery patients in Germany: results from a postal survey. Acta Anaesthesiologica Scand 2007;51:347-58. http://www.ncbi.nlm.nih.gov/pubmed/17096667

19. Hernandez AF, Li S, Dokholyan RS, et al. Variation in perioperative vasoactive therapy in cardiovascular surgical care: data from the Society of Thoracic Surgeons. Am Heart J 2009;158:47-52. http:// www.ncbi.nlm.nih.gov/pubmed/19540391

20. Shahin J, Devarennes B, Wing Tse C, et al. The relationship between inotrope exposure, six-hour physiological variables, and hospital mortality and renal dysfunction in patients undergoing cardiac surgery. Crit Care 2011;15:R162. http://www.ncbi.nlm.nih.gov/pubmed/21736726

21. Thackraya S, Easthaughb J, Freemantleb N, et al. The effectiveness and relative effectiveness of intravenous inotropic drugs acting through the adrenergic pathway in patients with heart failure-a metaregression analysis. Eur J Heart Fail 2002;4:515-29.

22. Dünser MW, Ruokonen E, Pettilä V, et al. Association of arterial blood pressure and vasopressor load with septic shock mortality: a post hoc analysis of a multicenter trial. Crit Care 2009;13:R181. http://www. ncbi.nlm.nih.gov/pubmed/19917106

23. Aninat C, Seguin P, Descheemaeker PN, et al. Catecholamines induce an inflammatory response in human hepatocytes. Crit Care Med 2008;36:848-54. 
24. West MA, Heagy W. Endotoxin tolerance: a review. Crit Care Med 2002;30. http://journals.Iww.com/ccmjournal/Fulltext/2002/01001/ Endotoxin_tolerance_A_review.9.aspx

25. Dellinger $\mathrm{RP}$, Levy MM, Carlet JM, et al. Surviving sepsis campaign: international guidelines for management of severe sepsis and septic shock: 2008. Crit Care Med 2008;36:296-327. http://www.ncbi.nlm. nih.gov/pubmed/18158437

26. Antman EM, Anbe DT, Armstrong PW, et al. ACC/AHA guidelines for the management of patients with ST-elevation myocardial infarction-executive summary: a report of the American College of Cardiology/American heart Association Task Force on practice guidelines (Writing Committee to Revise the 1999 Guidelines for the Management of Patients With Acute Myocardial Infarction). Circulation 2004;110:588-636. http://www.ncbi.nlm.nih.gov/pubmed/ 15289388

27. Reynolds HR, Hochman JS. Cardiogenic shock: current concepts and improving outcomes. Circ 2008;117:686-97. http://www.ncbi.nlm.nih. gov/pubmed/18250279

28. Valente S, Lazzeri C, Vecchio S, et al. Predictors of in-hospital mortality after percutaneous coronary intervention for cardiogenic shock. Int J Cardiol 2007;114:176-82. http://www.ncbi.nlm.nih.gov/ pubmed/16737749

29. De Backer D, Biston P, Devriendt J, et al. Comparison of dopamine and norepinephrine in the treatment of shock. New Engl J Med 2010;362:779-89. http://www.ncbi.nlm.nih.gov/pubmed/ 20200382

30. Vincent JL. "Let's give some fluid and see what happens" versus the "mini-fluid challenge". Anesthesiology 2011;115:455-6. http://www. ncbi.nlm.nih.gov/pubmed/21792055

31. Dempsey EM, Al Hazzani F, Barrington KJ. Permissive hypotension in the extremely low birthweight infant with signs of good perfusion. Arch Dis Child Fetal Neonatal Ed 2009;94:F241-4. http://www.ncbi. nlm.nih.gov/pubmed/19174413

32. Celi LAG, Tang RJ, Villarroel MC, et al. A clinical databasedriven approach to decision support: predicting mortality among patients with acute kidney injury. $J$ Healthc Eng 2011;2:97-110.

33. Frankovich J, Longhurst CA, Sutherland SM. Evidence-based medicine in the EMR Era. New Engl J Med 2011;365:1758-9. http:// www.nejm.org/doi/full/10.1056/NEJMp1108726

\section{APPENDIX}

Table Al The relationships between demographic/clinical variables and the propensity for receipt of vasoactive therapy

\begin{tabular}{|c|c|c|c|}
\hline & All patients, OR $(95 \% \mathrm{Cl})$ & $\begin{array}{l}\text { Treated patients, } \\
\text { OR }(95 \% \mathrm{Cl})\end{array}$ & $\begin{array}{l}\text { Fluid-resuscitated } \\
\text { patients, OR }(95 \% \mathrm{CI})\end{array}$ \\
\hline Age (year) & $0.99^{*}(0.99$ to 1.00$)$ & $0.99(0.98$ to 1.01$)$ & $0.99(0.98$ to 1.01$)$ \\
\hline Gender (male) & $1.55^{\star}(1.25$ to 1.92$)$ & $1.21(0.87$ to 1.67$)$ & 1.34 (0.83 to 2.18$)$ \\
\hline SAPS & $1.12^{*}(1.09$ to 1.14$)$ & $1.09^{*}(1.06$ to 1.13$)$ & $1.12^{*}(1.07$ to 1.17$)$ \\
\hline Elixhauser & $1.08^{*}(1.01$ to 1.17$)$ & $1.30 *(1.03$ to 1.64$)$ & NA \\
\hline $\begin{array}{l}\text { Mean MAP prior to HE } \\
(\mathrm{mm} \mathrm{Hg})\end{array}$ & 1.01 (0.99 to 1.02$)$ & 1.01 (0.99 to 1.03$)$ & 1.00 (0.98 to 1.03$)$ \\
\hline $\begin{array}{l}\text { Urine output prior to } \mathrm{HE} \\
>200 \mathrm{ml}\end{array}$ & $0.71^{*}(0.57$ to 0.88$)$ & 0.85 (0.61 to 1.18$)$ & 0.98 (0.60 to 1.59$)$ \\
\hline Creatinine prior to $\mathrm{HE}(\mathrm{mg} / \mathrm{dl})$ & $1.01(0.92$ to 1.11$)$ & $1.28^{*}(1.07$ to 1.52$)$ & $1.29^{*}(1.02$ to 1.64$)$ \\
\hline $\begin{array}{l}\text { Total volume of fluids given } \\
\text { prior to } H E(L)\end{array}$ & $1.01(0.97$ to 1.05$)$ & $1.01(0.96$ to 1.07$)$ & $0.97(0.89$ to 1.05$)$ \\
\hline \multicolumn{4}{|l|}{ Service type } \\
\hline MICU† & 1 & 1 & 1 \\
\hline SICU & $0.74(0.53$ to 1.03$)$ & $0.95(0.60$ to 1.50$)$ & $1.28(0.64$ to 2.56$)$ \\
\hline $\mathrm{CCU}$ & $1.37(0.97$ to 1.94$)$ & 1.68 (1.00 to 2.84$)$ & $1.41(0.59$ to 3.37$)$ \\
\hline CSRU & $2.06^{*}(1.55$ to 2.75$)$ & $2.84^{*}(1.87$ to 4.32$)$ & $3.56^{*}(1.91$ to 6.62$)$ \\
\hline Number of subjects & 2332 & 812 & 409 \\
\hline AUC & 0.726 & 0.703 & 0.729 \\
\hline Hosmer-Lemeshow $p$ value & 0.03 & 0.17 & 0.16 \\
\hline
\end{tabular}


Table All The relationships between demographic/clinical variables and the propensity for receipt of vasoactive therapy in different service types

\begin{tabular}{|c|c|c|c|c|}
\hline & MICU, OR (95\% CI) & SICU, OR (95\% CI) & CCU, OR (95\% CI) & CSRU, OR (95\% Cl) \\
\hline Age (year) & $0.99(0.98$ to 1.00$)$ & $0.99(0.98$ to 1.01$)$ & $0.99(0.96$ to 1.01$)$ & $1.00(0.99$ to 1.01$)$ \\
\hline Gender (male) & $1.86^{*}(1.20$ to 2.87$)$ & 1.45 (0.84 to 2.49$)$ & 1.50 (0.84 to 2.69$)$ & $1.60^{*}(1.14$ to 2.24$)$ \\
\hline SAPS & $1.16^{*}(1.11$ to 1.21$)$ & $1.15^{\star}(1.09$ to 1.21$)$ & $1.15^{\star}(1.09$ to 1.21$)$ & $1.04^{*}(1.00$ to 1.09$)$ \\
\hline Elixhauser & $1.04(0.91$ to 1.20$)$ & 1.09 (0.93 to 1.29$)$ & $1.23^{*}(1.02$ to 1.49$)$ & $1.05(0.93$ to 1.18$)$ \\
\hline $\begin{array}{l}\text { Mean MAP prior to } \mathrm{HE} \\
(\mathrm{mm} \mathrm{Hg})\end{array}$ & $1.00(0.98$ to 1.03$)$ & 1.01 (0.99 to 1.04$)$ & $1.03(1.00$ to 1.06$)$ & $0.99(0.97$ to 1.01$)$ \\
\hline $\begin{array}{l}\text { Urine output prior to } \mathrm{HE} \\
>200 \mathrm{ml}\end{array}$ & $0.57^{*}(0.36$ to 0.92$)$ & $0.50^{*}(0.29$ to 0.86$)$ & $1.29(0.74$ to 2.25$)$ & $0.72^{*}(0.52$ to 1.00$)$ \\
\hline Creatinine prior to $\mathrm{HE}(\mathrm{mg} / \mathrm{dl})$ & $1.10(0.96$ to 1.27$)$ & $1.10(0.90$ to 1.35$)$ & $1.09(0.88$ to 1.36$)$ & $0.57^{*}(0.40$ to 0.79$)$ \\
\hline $\begin{array}{l}\text { Total volume of fluids given } \\
\text { prior to HE (L) }\end{array}$ & $1.03(0.95$ to 1.13$)$ & $1.02(0.92$ to 1.14$)$ & $0.99(0.89$ to 1.11$)$ & $1.00(0.94$ to 1.07$)$ \\
\hline Number of subjects & 692 & 535 & 379 & 726 \\
\hline AUC & 0.751 & 0.748 & 0.740 & 0.603 \\
\hline Hosmer-Lemeshow $p$ value & 0.71 & 0.01 & 0.93 & 0.33 \\
\hline
\end{tabular}

Each column represents a separate propensity score model for a specific service type.

*Statistically significant.

AUC, area under the receiver operating characteristic curve; CCU, coronary care unit; CSRU, cardiac surgery recovery unit; HE, hypotensive episode; MAP, mean arterial pressure; MICU, medical intensive care unit; SAPS, Simplified Acute Physiology Score; SICU, surgical intensive care unit.

Table All The vasoactive therapy propensity score analysis results for inhospital mortality in different service types

\begin{tabular}{|c|c|c|c|c|}
\hline & MICU, OR (95\% CI) & SICU, OR (95\% Cl) & CCU, OR (95\% CI) & $\begin{array}{l}\text { CSRU, OR } \\
(95 \% \mathrm{CI})\end{array}$ \\
\hline Fluid resuscitation & $1.02(0.62$ to 1.69$)$ & $0.64(0.30$ to 1.37$)$ & $0.52(0.17$ to 1.61$)$ & 2.14 (0.84 to 5.46$)$ \\
\hline Use of vasoactive agents & $2.90^{*}(1.82$ to 4.61$)$ & $4.53^{\star}(2.46$ to 8.34$)$ & $3.20^{*}(1.58$ to 6.48$)$ & 0.71 (0.27 to 1.89$)$ \\
\hline $\begin{array}{l}\text { Propensity for vasoactive } \\
\text { therapy }\end{array}$ & $\begin{array}{l}70.20^{*} \\
(17.86 \text { to } 275.94)\end{array}$ & $\begin{array}{l}147.57^{*} \\
(19.39 \text { to } 1122.96)\end{array}$ & $\begin{array}{l}186.24^{*} \\
(24.41 \text { to } 1420.79)\end{array}$ & $\begin{array}{l}0.00^{*} \\
(0.00 \text { to } 0.43)\end{array}$ \\
\hline Number of subjects & 692 & 535 & 379 & 726 \\
\hline AUC & 0.729 & 0.751 & 0.791 & 0.645 \\
\hline Hosmer-Lemeshow $p$ value & 0.29 & 0.02 & 0.33 & 0.37 \\
\hline
\end{tabular}

